\title{
Snakehead fish, Haruan (Channa striata): Emerging potential for nutraceuticals, active pharmaceutical ingredients (API) and biomedical applications
}

\author{
ABDULL MANAN MAT JAIS*, AHMAD KHUSAIRI AZEMI, MOHAMMAD HAFIZ \\ ABDUL RAHIM, SADEGH ABEDI, IRMA IZANI MOHAMAD ISA, MEERA \\ KUPPUSAMY ${ }^{1}$, TARITA TAIB ${ }^{1}$ AND M. AMINUR RAHMAN ${ }^{2}$ \\ Abmanan Biomedical Sdn bhd, 38, Arked MARA Kajang, Jalan Reko, 43000 Kajang, Selangor, Malaysia \\ ${ }^{1}$ Faculty of Medicine, UiTM Selayang Campus, Jalan Prima Selayang, Selangor, \\ ${ }^{2}$ Dept.of Fish. \& Marine Bioscience, Jashore University of Science \& Technology, Jashore, Bangladesh \\ *E -mail: abdullmanan_matjais@yahoo.com \\ A keynote given at the Fisheries Society of Bangladesh Biennial Conference on \\ Fisheries in the Bangladesh Blue Economy-Challenges and Opportunities, December 27-28, 2019
}

\begin{abstract}
This is a collaborative effort between Malaysia and Bangladesh to introduce and promote the striped-snakehead Haruan Channa striata (Bloch 1793) or Shol in Bangladesh as natural product resources for food, cosmetic and pharmaceutical industry. The objective is to involve up-scaling biotechnological activity to prepare by-product(s) utilizing every-parts of the fish. The project will reduce organic waste, generate higher revenue and improve quality-life of farmers. Here is a case-study as a reference, reviewing outcome of a drug discovery R \& D on the species in Malaysia since 1985 where Haruan, a good source of protein, the undisputed oral traditional medicine inducing quick recovery for ladies after giving birth. Accordingly, stock identification and environmental physiology data of this indigenous species were obtained: inhabiting warm, clean, shallow slow-running or stagnant water with aquatic-flora or dead-wood as hiding/resting place ambushing preys. This information is key to a sustainable commercial-scale aquaculture Haruan AgroPharmaceutical Industry (HAPI); comprising pre-harvest; and extended to post-harvest activities. The establishment is to maintaining and sustaining the unique biochemistry reflecting carnivorous behavior consuming other fishes, amphibians and reptiles. The fish contains high-protein $(\geq 60 \%)$, low-fat $(<3 \%)$ and comprehensive dietary minerals with a good amino acid profile, high in Glycine and fatty acid with $\Omega-6$ (Arachidonic Acid), $\Omega-3$ (Docasahexaenoic Acid or DHA), albumin and cyclic-peptide N-arachidonylglycine @ NAGly. Hence, a proprietary standard operating procedure as a technology had been established, and successfully performed for extracting the biochemistry through a Pressurized In-Water Extraction (PIWE). The extract is termed as Haruan Manan (HM). However, actual protocol is a trade-secret. It is a bioactive, key ingredient in every Haruan Biomedical Product (HBP) inducing wound-healing, reducing-pain, treating inflammation and inhibiting growth of pathogenic bacteria (including Staphylococcus aureus and Helicobacter pylori). These four physiological steps to healing, curing and treating are demonstrated by our first product: Haruan Cream containing 5\% of the HM for skin disease, eczema. HM is a signature, Active Pharmaceutical Ingredient (API); and we are discussing, demonstrating and high-lighting potential of $C$. striata as functionalfood, nutraceuticals and API.

Keywords: Snakehead, Channa striata, Biomedical products, Nutraceuticals
\end{abstract}

\section{Introduction}

Malaysia is one of the world's mega-biodiversity zone, having 614 species of freshwater fishes. Some are ornamental and many are food fishes. One of the prominent species is the undisputed oral traditional medicine in helping ladies after child delivery is Haruan C. striata (Mat Jais 2007a, Mat Jais 2007b, Wahab et al. 2015). The fish is called Shol in Bangladesh. Haruan 
together with other seven species of the family Channidae including giant-snakehead or Toman C. micropeltes, Bujuk C. Lucius and black snakehead or Haruan-hitam C. melanosoma are found in Malaysia (Mohsin and Ambak 1983, Lee and $\mathrm{Ng} \mathrm{1994).} \mathrm{It} \mathrm{is} \mathrm{game} \mathrm{to} \mathrm{freshwater}$ anglers, good source of protein and more importantly is the ethno-pharmacology, the traditional medicine inducing quick recovery for ladies in post-partum. Based on that ethno-pharmacology, a drug discovery R \& D on the species had been carried out since 1985; and one of the most important outcomes or discovery is a protocol, a biotechnology; a standard operating procedure (SOP) in extracting the biochemistry in Haruan that is responsible for the medicinal value (Mat Jais 2007a, Mohd Safri and Abdull Manan 2012). The extract is termed as Haruan Manan (HM), key ingredient, bioactive and to be made an active pharmaceutical ingredient (API). Subsequently, we had formulated and produced a natural product, non-steroidal and noncarcinogenic Haruan Cream (HC) containing HM as API for a no-cure chronic inflammation of the skin eczema (Fig. 1).

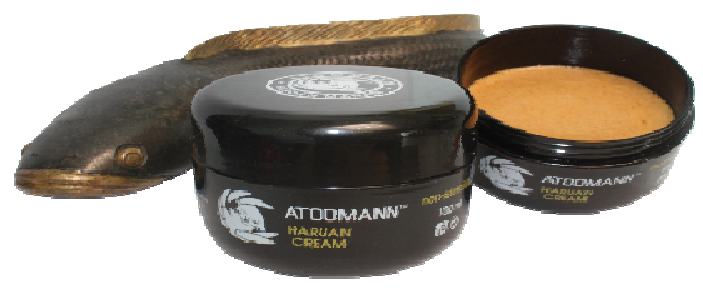

Fig. 1. A container containing $100 \mathrm{~g}$ Haruan cream

C. striata, an indigenous species to Malaysia based on Restriction Fragment Length Polymorphism (RFLP) where six-nucleotide sequences with accession no JF826031 - JF 826036 as marker has been deposited in GenBank (Kajima et al. 1994, Ahmad Khusairi 2011, Rahim et al. 2011). This air-breather is carnivorous and monogamous species that has been already in Malay Peninsular for more than 100,000 years, almost the same time when Titiwangsa Mountain Range was formed. Nonetheless, the species is also reportedly inhabiting Bangladesh and other ASEAN countries- Brunei, Singapore, Indonesia, Philippines and Thailand (Mohsin and Ambak 1983, Hossain et al. 2008). However the species is also cited and caught in higher altitude with lower water temperature. The species preys on other fishes, amphibians and reptiles to provide a unique comprehensive dietary nutrient to making the fish almost complete as functional-food. Furthermore, besides the traditional medicine inducing quick recovery, wound-healing for both either normal or through a lower abdominal segment surgery caesareansection; Haruan or Shol is also having great potential, highly promising to be developed for other issues such as allergy, diabetic-gangrene and bed-sore or decubitus (Mat Jais 2007a, Haniffa et al. 2014, Wahab et al. 2015). However, now the fish is having a much-wider spectrum also used for helping those involving road accidents, general and specific clinical surgery.

We are pursuing a collaborative effort between two countries Malaysia and Bangladesh to working on multidisciplinary aspects of both pre-harvest and post-harvest activities, especially 
ABDULL MANAN MAT JAIS et al.

here in Bangladesh. The project will primarily on Haruan $C$. striata, but might also involving different other species namely Tilapia, in a various possible opportunities

\section{Materials and Methods}

Distribution: A traditional, conventional-questionnaire-based field survey was done for gathering as much biological information on the species. We visited almost every possible location in both West (Semenanjung Tanah Melayu (STM) or Peninsular Malaysia) and East Malaysia (Sabah and Sarawak) in Borneo. This was performed with help of local-guidance especially villagers, farmers, fishermen, fish-sellers, anglers and staff of Department of Fisheries; and five main research stations were selected (three in Peninsular and one each in Sabah and Sarawak) throughout Malaysia. Wild Haruan was fished in each visited location to reconfirming existence, and external morphology examination was carried-out. If necessary, a thorough examination was carried-out in laboratory as not to be mistaken with a closely lookalike Haruan Hitam or Black-Haruan $C$ melanosoma. External morphology of Haruan C. striata was illustrated (Azis 1988, Azemi 2012, Mat Jais 2007a)

Environmental physiology: Physical measurement of the water where wild Haruans were caught was analysed using HORIBA U-10 Water Quality Checker on depth, temperature, $\mathrm{pH}$, turbidity, conductivity and Dissolve-Oxygen (DO). At the same-time observation in naturalhabitat were made on feeding-habits, reproduction and parental-care. A total of 120 specimens of wild Haruan were collected from sampling stations in Johor, Kedah, Kelantan, Pahang, Perak and Terengganu (Hafiz et al. 2009)

Genetic markers: Five adults wild Haruan caught in three research stations in STM or West Malaysia were analysed based on Restriction Fragment Length Polymorphism (RFLP), to distinguish individuals, populations or species of Haruan C. striata in Malaysia (Kajima et al. 1994, Ahmad Khusairi 2012). It was followed by analysis of mtDNA cyt $b$ using PCR - RFLP technique involving 120 fishes, investigating genetic variation of $C$. striata among populations in Peninsular Malaysia (Abdul Rahim et al. 2012)

Biochemistry: Fresh midline fillet of Haruan was homogenised in chloroform:methanol 2:1 v/v and the aqueous portion was siphoned as stock. First, $2 \mathrm{ml}$ aliquot of this stock was placed in 5,000, 10,000 and 30,000 NMWL (Nominal Molecule Weight Limit), Millipore Ultra free-CL low binding cellulose filter; centrifuged for $10 \mathrm{~min}$ at 5,000 rpm. Series of 0, 25, 50 and $100 \%$ of the 30,000 NMWL filtered samples were prepared in distilled water for the constriction test, followed by 5, 10 and $25 \%$ of the 10,000 and 5,000 NMWL samples, determining molecular size which was responsible for antino-ciceptive. Subsequently, $1 \mathrm{ml}$ of the non-filtered, 5,000 and 10,000 NMWL filtered samples was purified through an analytical column with multiple injections and collection of material Hewlett Packard HPLC at $1 \mathrm{~mL} \mathrm{~min}^{-1}, 205 \mathrm{~nm}, 5 \%$ $\mathrm{CH}_{3} \mathrm{OH} / \mathrm{H}_{2} \mathrm{O}$ for $20 \mathrm{~min}$ followed by $100 \% \mathrm{CH}_{3} \mathrm{OH}$. The fraction collected between $1-3 \mathrm{~min}$ was dried under vacuum yielding $30 \mathrm{mg}$ of extracts, reconstituted in distilled water to a concentration of $0.0005,0.005,0.05$ and $0.5 \mathrm{mg} \mathrm{mL}^{-1}$ in distilled water and used in abdominal constriction test in mice according to method described by Mat Jais et al. (1997) 


\section{Biomedical analysis}

Animal model: This was to identify properties of Haruan Cream (HC) containing 5\% Haruan's extract, Haruan Manan (HM). It is a natural product on myeloperoxidase enzyme as a marker of polymorphonuclears accumulation. Anti-inflammatory activity of the HC (at doses 1, 5 and $10 \%$ ) on ear thickness and myeloperoxidase activity (the two acute inflammation indexes) were studied using croton oil induced ear-oedema method. It was comparied with effects of hydrocortisone $1 \%$ cream as reference drug (Sadegh Abedi et al. 2012) five mice in each six groups Male ICR were subjected to three $\mathrm{HC}$ treatment groups, (HM $1 \%, 5 \%$ and $10 \%$ ) to analyse effects, together with acetone (a vehicle), TPA alone (a negative control), and hydrocortisone $1 \%$ (positive control). Both surfaces of mouse ears were briefly applied with TPA $(2.5 \mu \mathrm{g} / 20 \mu \mathrm{l}$ acetone) for five times on alternate days, $\mathrm{HC}$ or hydrocortisone $1 \%$ cream for the last three days. Mouse ear thickness was measured $24 \mathrm{~h}$ after final treatment with HC and cut for further histological analysis and gene expression studies of TNF- $\alpha$ by real-time reverse transcriptase-polymerase chain reaction (RT-qPCR) (Izani et al. 2016)

Human model: A double blind randomized trial was conducted based on European Task Force on Atopic Dermatitis (ETFAD), the SCORAD INDEX evaluating safety of the HC (Phase 1) and effectiveness (Phase 2).

Phase 1: evaluation on safety of HC for topical-application was done on 83 healthy skin adolescent-volunteers who fulfilled the inclusion criteria; to undergo patch testing. The allergens, aqueous and $\mathrm{HC}$ containing $5 \%$ of $\mathrm{HM}$, were patch-tested simultaneously but separately on each arm of the same participant. The participants with a negative patch-test started stage 2, applied randomly assigned creams on both forearms for duration of 1 month.

Phase 2: Determination on effectiveness of the HC involved 180 (145 females, 35 males), aged 16 to 30 years (mean 23.49 years \pm 3.52 ) with mild to moderate Atopic Eczema (AE). They were enrolled and randomly assigned to receive either two treatments $\mathrm{HC} 5 \%$ cream or Betamethasone Valerate Cream (BVC) $0.025 \%$ as positive control, for four weeks with a crossover. Every patient was subjected to Scoring atopic dermatitis (SCORAD), eczema area severity index (EASI) and Dermatology quality of life index (DLQI) were assessed at baseline and two weekly for others except DLQI (four-weekly interval).

\section{Results and Discussion}

Distribution: Haruan is widely distributed throughout Malaysia, and the five research stations selected for the project as illustrated in Fig. 2. The fish was caught in almost every water body, both natural as well as man-made habitats. Haruan is also invasive into other species' aquaculture, which sometimes if not most of the time giving extra-revenue due to a higher between RM 20 - 30 per kilogram compared to Tilapia and Catfish. However, the fish is not as popular, or daily food due to higher prizing, but well sorted as medicine (Mat Jais 2007a, Mohd Safri and Abdull Manan 2012). The other species that look-alike Haruan or Shol or common snakehead fish C. striata is Haruan Hitam or Balck Haruan C. melanosoma as shown in Fig. 3. 


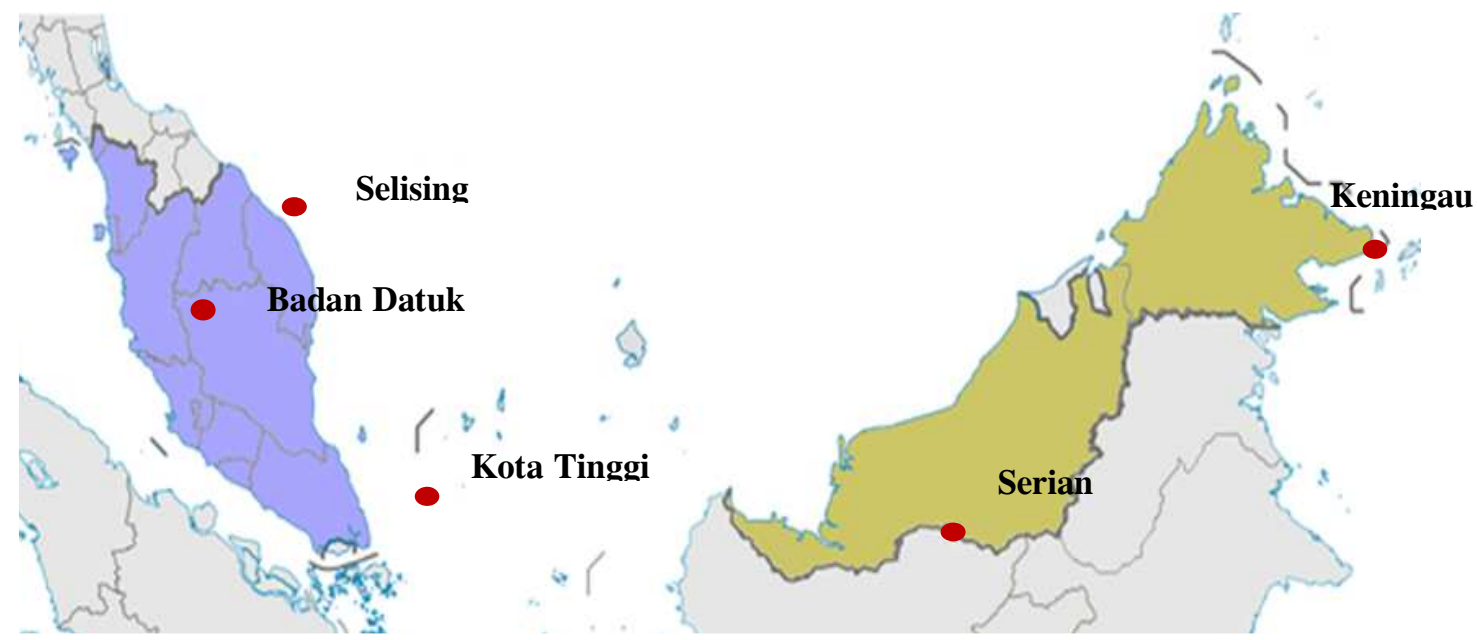

Fig. 2. Map of Malaysia with the Five Main Research Stations.

This Map is Adopted from https://en.wikipedia.org/wiki/States_and_federal_territories_of_Malaysia.

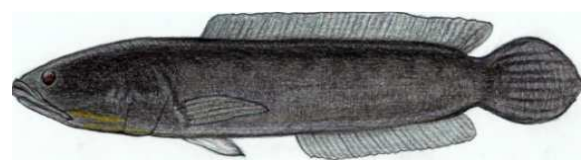

Haruan Channa striatus

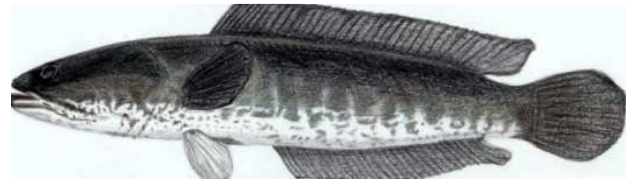

Black Haruan Channa melanosoma

Fig. 3. Two Species of Snakeheads are found to have almost a similar Physical Morphology in Malaysia waters.

Environmental physiology: Natural habitat of Haruan were small, either stagnant or slowrunning, shallow water body between 0.2 to 2 meters, temperature within $29.43-31.86^{\circ} \mathrm{C}, \mathrm{pH}$ between 5.16 - 6.90, Dissolved Oxygen (DO) $2.62-33.70 \mathrm{mg} \mathrm{L}^{-1}$, turbidity between -10.00 to 14.57 NTU; conductivity of $0.06-0.97 \mathrm{mScm}-1$ and salinity of $0-20 \mathrm{ppt}$, summarized in Table I. This is a specific environmental physiology of the species, where it was caught, and to become reference, a guide, a standard in setting farming activities to yield a desired quality, ensuring authenticity and originality of the raw-material as required by CITES (Convention on International Trade in Endangered Species) of Wild Fauna and Flora, also known as the Washington Convention. This ecological data is contributing to ensure Haruan is not in the redlist of the International Union for Conservation of Nature (IUCN), as an endangered, or to become extinct species as requirement to making the species as raw-material for any by-product. 
Table I. Physical parameters of the water where wild Haruan $C$. striata is found

\begin{tabular}{l|c}
\hline \multicolumn{1}{c|}{ Parameters } & Measurements \\
\hline Depth & $0.2-2$ meters \\
\hline Temperature & $20-28^{\circ} \mathrm{C}$ \\
\hline Dissolved-Oxygen & $1-4.1 \mathrm{ppm}$ \\
\hline $\begin{array}{l}\text { Conductivity (ability or power to conduct or } \\
\text { transmit heat, electricity, or sound) }\end{array}$ & $0.1-1.3$ Siemens per meter $\left(\mathrm{S} / \mathrm{m} \mathrm{or} \mathrm{mScm}^{1}\right)$ \\
\hline $\begin{array}{l}\text { Turbidity (clarity, cloudiness or haziness of } \\
\text { water). This is associated to concentration of } \\
\text { suspended particles in water, that might block } \\
\text { light penetration, and productivity }\end{array}$ & $2-20 \mathrm{ppm}$ or nephelometric turbidity units \\
\hline $\mathrm{pH}$ & $5.5-7.5$ \\
\hline Salinity & $0-10 \mathrm{ppm}$ \\
\hline
\end{tabular}

Other parameter considered was Total Dissolved Solids (TDS), Redox Potential or Oxidation-Reduction Potential (ORP). This is measuring water ability to oxidize contaminants. The higher the ORP, the greater number of oxidizing agents is available. Ion Concentration Analysis and Water Hardness (amount of dissolved calcium and magnesium) had also determined where the water was having chemical composition (ammonia, phosphate, sulphate, chlorine, calcium, magnesium and sodium) well below toxic level to human (Mat Jais 1991, 1995, 1997; Mat Jais et al. 1992 \& 2001). Haruan is inhibiting water-body with plenty of aquatic plants and dead-woods as shelter, a resting and hiding place

Genetics: Although Haruan in Malaysia is divided into 2 major clades, but there was no significant relationship between genetic distance and geographic distance was detected. The estimated time of population expansion in the mtDNA cyt $b$ of $C$. striatus populations occurred 0.72 - 6.19 million years ago. Genetic diversity of mtDNA cyt $b$ and population structure among Haruan populations in Peninsular Malaysia will be useful in fisheries management for standardization for Good Agriculture Practices (GAP) in fish-farming technology, as well as providing the basis for Good Manufacturing Practices (GMP).

Stock Identification study using a RFLP is another standardization practice, and a must to identify parentage or brood-stock for breeding where the fish is found to having 44 chromosomes (Mat Jais 1991, 1995, 1997; Mat Jais et al. 1992 \& 2001). Furthermore, the RFLP measurement had clearly shown that Haruan is an indigenous species to Malaysia, one of keyfinding in this project (Abdul Rahim et al. 2012, Azemi 2012). In relation to this, a six of the nucleotide sequences of the local wild Haruan had been identified, deposited at GenBank with accession no: JF826031 - JF 826036 as marker (Abdul Rahim et al. 2012). It is a marker, vital information in the case of double-claimed by other country, disputing status of Haruan. It also helps in commercial-cheat when people are claiming their product is containing Haruan, or a fake and blaming us if bad-incident happening. This molecular or genetic-marker is an important finger-printing of Haruan C. striatus and it is a standardization.

Biochemistry: as expected, the 30,000 NMWL filtered samples has produced a dose dependent antinociceptive activity. Nonetheless each of the 25, 50 and $100 \%$ concentration of the 5,000, 10,000 and 30,000 Dalton filtered-samples and the HPLC fraction $(\mathrm{Ht}=1-3 \mathrm{~min})$ had also 
produced inhibition in the abdominal constriction tests, indication anti-pain property. Even at lower concentration 5, 10 and $25 \%$ dosage of all the filtered samples had produced dose dependent activity; and significantly different at $p<0.01$ (Mat Jais 2007a). Therefore the molecular size of the active-compound or bioactive in HM is ranging from less than 5,000 to 30,000 NMWL. Furthermore, the bioactive compound in $\mathrm{HM}$ is stable at $\mathrm{pH} 6-8$ and temperature up to $100^{\circ} \mathrm{C}$ during cooking; as well as was not digested by enzymes $\alpha$-amylase protease and lipase. This is an extension of the earlier report that the $C$. striata contains all the essential amino and good profile of fatty acids for wound healing (Azis et al. 1990, Mat Jais et al. 1994, Mat Jais et al. 1998, Dahlan-daud et al. 2010, Zuraini et al. 2006)

Biomedical animal model: Haruan Cream (HC) is having similar potent with reference treatment, significantly inhibited oedema at 4 and $24 \mathrm{~h}$ after croton oil application $(p<0.05)$. Besides, myeloperoxidase assay, results shown that topical application of the three different dosages of HC had blocked migration of polymorphonuclear leukocytes to the dermis as effective as hydrocortisone cream $1 \%$ and in a dose dependent manner $(p<0.05)$. Evidences obtained from the study, is supporting the previous results that had shown the anti-inflammatory effects of Haruan extracts in other animal models; and strongly suggesting that topical antiinflammatory effects of $\mathrm{HC}$ haruan contributed to its bioactive substances content such as linoleic acid, stearic acid, oleic acid and $\mathrm{N}$-arachidonylplycine (Abedi et al. 2012). Topical application of $\mathrm{HC}$ had reduced the mouse ear thickness 18.1 - $28 \%$ ) with comparable effect to the positive control. In addition, histopathological comparison shown evident of reduction in various parameters of cutaneous inflammation including dermal oedema, inflammatory cells infiltration and proliferation of epidermal keratinocytes. Furthermore, TPA application resulted in the up-regulation of TNF- $\alpha$ gene expression by 353-fold, which was subsequently downregulated by the Haruan Cream, 34 to 112-fold (Izani et al. 2016).

Biomedical human model: The extract is a potential source of useful drugs; and this article is to updating research findings on potential uses of $C$. striata, beyond the traditional prescription as a wound healer, pain reliever and energy booster. The properties included ACE-inhibitor, anti-depressant and neuro-regenerative agent (Ghassem et al. 2011, Saleem et al. 2011). The fish appears to have wide-range of medical uses and should be studied more intensively to understand its other properties and mechanisms of action (Mat Jais 2007, Mohd Safri and Abdull Manan 2012).

On top of anti-pain (Mat Jais 1997), anti-inflammation is another area of focus to found that 1, 5 and $10 \% \mathrm{HM}$ in Haruan Cream (HC) had significantly inhibited mice ear-edema at 4 and 24 hours. Furthermore, based on myeloperoxidase (MPO) essays, the topical application of the $\mathrm{HC}$ also blocked migration of polymorphonuclear leukocytes to the dermis, as effective as that of steroid based hydrocortisone cream 1\% (Abedi et al. 2012). It is suspected that the polyunsaturated fatty acid docosahexaenoic acid (DHA) and eicosapentaenoic acid (EPA) in Haruan extract is responsible for the anti-inflammation properties (Mat Jais, 2007, Abedi 2012). This followed by a finding that $\mathrm{HC}$ has down-regulates tumor necrosis factor (TNF)-alpha gene expression and alleviates chronic-like dermatitis in mouse model (Izani et al. 2016). Subsequently, a human model evident from a randomized double blind clinical trial evaluating safety (Phase 1) and efficacy (Phase 2) of the $\mathrm{HC}$ had demonstrated positive results. The Phase 1, only 2 or $2.4 \%$ had developed irritant reaction towards HC, where the other 81 or $97.6 \%$ volunteers; adolescent healthy skin individuals, did not report any adverse effects. Furthermore, 
all the 180 patients with mild eczema subjected to the $\mathrm{HC}$ containing $5 \% \mathrm{HM}$ in the Phase 2 clinical trial had shown a positive respond where the mean SCORAD reduction from baseline in the CS 5\% group was $2.05(p<0.001)$ and $3.42(p<0.001)$ in the betamethasone valerate cream (BVC) $0.025 \%$ group. Although, there was no significant difference between groups $\mathrm{HC}$ versus BVC by SCORAD, EASI and DLQI at week four, but the HC is safe and effective in reducing disease severity in mild to moderate $\mathrm{AE}$ cases. This uniquely natural product, nonsteroidal and non-carcinogenic $\mathrm{HC}$ has a good safety profile and tolerability obtained from Phase 1 is indeed potential to be developed to treating inflammatory skin conditions, namely eczema.

\section{Conclusions}

The whole project is summarized in a conceptual representative: Haruan Agro-Pharmaceutical Industry (HAPI) combining every aspect of both pre-harvest and post-harvest activities as in Fig. 4.

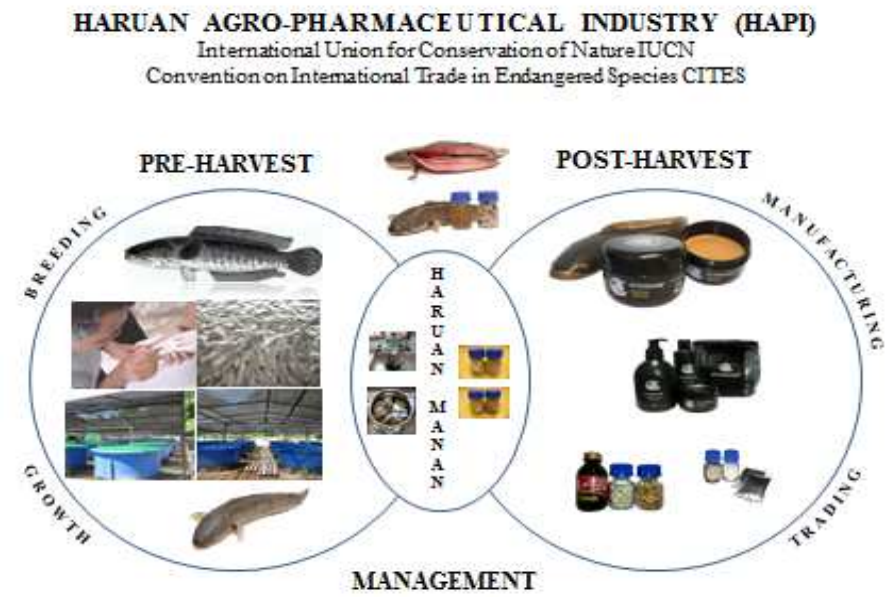

Fig. 4. A conceptualized holistic activities of the project as Haruan Agro-Pharmaceutical Industry (HAPI).

The concept is complying requirement of both domestic and international regulatory to produce Haruan as natural product raw-material for food, cosmetic and pharmaceutical industry. This concept can easily be adapted to other species, ensuring good management, environmental friendly and a sustainable industry. It is a pre-requisite for Haruan's extract, the Haruan Manan (HM) with medicinal value inducing wound-healing, reducing pain, treating inflammation and inhibiting growth of pathogenic bacteria Staphylococcus auerus to become Active Pharmaceutical Ingredient or API (Mat Jais et al. 1998, Mat Jais 2007b, Mohd Safri and Abdull Manan 2012, Rahman et al. 2018). The properties are well incorporated in HC that contains 5 $\%$ HM which had demonstrated a significant-effects on topical inflammatory in both animal and human model (Abedi et al. 2012, Izani et al. 2016). It is a uniquely Malaysian innovation, the $\mathrm{HC}$ is having a good safety profile. This information on safety and tolerability obtained will be used to design larger phase II studies in patients with inflammatory skin conditions, comparable 
ABDULL MANAN MAT JAIS et al.

to Betamethasone Valerate Cream (BVC). It will therefore be interesting and exciting to extend the work in Bangladesh for there is already a research study on eczema in the country (Karim et al. 2013). However, this HC is not just for the still no-cure chronic inflammatory, eczema but also for other illnesses such as psoriasis, allergy, diabetic-gangrene and bed-sore. It is therefore, both HM and HC are indeed a good example to initiating a paradigm-shift from traditional to an advance-fishery industry. It will open-up new perspective, a wider spectrum into what fishery can contribute to community and GDP of a nation.

\section{Literature Cited}

Abdul Rahim, M.H., A. Rozila and A.M. Mat Jais, 2009. The Physical-chemical and morphological study of Haruan Channa striatus in Peninsular Malaysia. Res. J. Biol. Sci., 4(9): 994 - 1009.

Abdul Rahim, M.H., P. Ismail, R. Alias, N. Muhammad and A.M. Mat Jais, 2012. PCR-RFLP analysis of mitochondrial DNA cytochrome b gene among Haruan (Channa striatus) in Malaysia. Gene, 494 (1): $1-10$.

Abedi, S., F.E. Far, M.K. Hussain, A. Zuraini and A.M. Mat Jais, 2012. Effects of Haruan (Channa striatus) based cream on acute inflammation in Croton Oil Induced Mice Ear Edema Model. Res. J. Biol. Sci., 7(5): 181 - 187.

Azemi, A.K., 2012. Stock identification study of Channa striatus in Peninsular Malaysia. B.Sc Thesis Submitted to Department of Biomedical Sciences, Faculty of Medicine and Health Sciences, Universiti Putra Malaysia.

Azis, S., 1988. Environmental physiological aspects of Haruan Channa striatus in Sabah. B.Sc Thesis submitted to Department of Biology, Faculty of Science and Natural Resources, Universiti Kebangsaan Malaysia Campus Sabah.

Azis, S., I.M. Yusof and A.M. Mat Jais, 1990. Protein and amino acids composition in Haruan. Proc. Natl. Chem. Anal., 1, 3 p.

Dahlan-Daud, C.K., A.M. Mat Jais, Z. Ahmad, A.M. Akim and A. Adam, 2010. Amino and fatty acids composition in haruan traditional extract. Boletin Latino-americano y del Caribe de Plantas Medicinales y Aromaticas, 9: 414 - 429.

Ghassem, M., K. Arihara, A.S. Babji, M. Sais and S. Ibrahim, 2011. Purification and identification of ACE inhibitory peptides from Haruan (Channa striatus) myofibrillar protein hydrolysate using HPLC-ESI-TOF MS/MS. Food Chem, 129 (4): 1770 - 1777.

Haniffa, M.A.K., P.A. JeyaSheela, K. Kavitha and A.M. Mat Jais, 2014. Salutary value of haruan, the striped snakehead Channa striatus - a review. Asian Pac. J. Tropic. Biomed., 4(1): S8 - S15.

Hossain, M.K., G.A. Latifa and M.M. Rahman, 2008. Observations on induced breeding of snakehead murrel, Channa striatus (Bloch, 1793). Int. J. Sustain. Crop Prod., 3: 65 - 68.

Izani, I., M. Isa, S.A. Bakar, S.F.M. Tohid and A.M. Mat Jais, 2016. Channa striatus cream downregulates tumour necrosis factor (TNF)- alpha gene expression and alleviates chronic-like dermatitis in mouse model. J. Ethnopharmacol., 194: 469 - 474.

Karim, M.E., C.M. Ali and N. Akhtar, 2013. Clinical study on atopic dermatitis. Bangladesh Med. J., 42(1): $18-20$.

Kuppusamy, M., T. Taib, A. Johar and A.M. Mat Jais, 2018. Topical Channa striatus 5\% cream for inflammatory skin conditions: A phase I randomized double-blind, controlled trial. Iran J. Dermatol., 19: $67-72$.

Lee, P.G. and P.K.L. Ng, 1994. The systematics and ecology of snakeheads (Pisces: Channidae) in Peninsular Malaysia and Singapore. Hydrologia, 285: 59 - 74.

Mat Jais, A.M 1997. Haruan Channa striatus as a component of health food. Proc. Asian Food Technol. Seminar, $39-43$.

Mat Jais, A.M., 1991. Haruan, Channa striatus, Farming in Backyard. Proc. 3rd Asian Conference of Technology for Rural Development, 91, 230 - 232. 
Mat Jais, A.M., 2007b. Pharmacognosy and pharmacology of Haruan (C. striatus), a medicinal fish with wound healing properties," Boletin Latinoamericano y del Caribe de Plantas Medicinales y Aromaticas, 6: $52-60$.

Mat Jais, A.M., K. Prasat and K.D. Croft, 2001. Distribution, environmental physiology and genetic variability of Haruan Channa striatus. Malay. Fish. J., 2(1): $192-197$.

Mat Jais, A.M., R. Fung and E. Bosi, 1992. Haruan and Wound Healing. Proc. First Sym. National Natural Resources, 23 - 26 July, 1992, Kota Kinabalu, 52 p.

Mat Jais, A.M., R. Fung, E. Bosi, C. Platell, R. McCauley and K. Croft, 1998. Preliminary evidence on the potential of Haruan. Malay. Appl. Biol., 27: $50-51$.

Mat Jais, A.M., R. McCulloch and K. Croft, 1994. Fatty acid and amino acid composition in haruan as a potential role in wound healing. Gen. Pharmacol, 25: $947-950$.

Mat Jais, M.A., 2007a. Molecular size of the bio-active Components from Haruan Channa striatus extract. J. Appl. Sci., 7: 2198-2199.

Mohd Shafri, M.A. and M.J. Abdul Manan, 2012. Therapeutic potential of the haruan (Channa striatus): from food to medicinal uses. Malay. J. Nutr., 18 (1): 125 - 136.

Mohsin, K. and M.A. Ambak, 1983. Freshwater fishes of peninsular Malaysia, Universiti Pertanian Malaysia Press, Kuala Lumpur. 284 p.

Ngui, W.S.Y., N.H. Hassan, N. Ramlan and S.I. Zubairi, 2017. Malaysia snakehead Channa striatus and Channa micropeltes: Physico-chemical properties of fillet fish oil and water-soluble extract. Italian Assoc. Chem. Eng. AIDIC, 56 (6): 61 - 66.

Rahman, M.A., M.H.R. Molla, M.K. Sarker, S.H. Chowdhury and M.M. Shaikh, 2018. Snakehead fish (Channa striata) and its biochemical properties for therapeutics and health benefits. SF J. Biotechnol. Biomed. Eng., 1(1): 1 - 5.

Saleem, M.A., A.M. Mat Jais, S. Fakurazi, M. Moklas, M.R. Sulaiman and M.R. Amom, 2011. Antidepressant-like effect of aqueous extract of Channa striatus fillet in mice models of depression. Eur. Rev. Med. Pharmacol. Sci., 15: 795 - 802.

Wahab, A., S.Z.A.A. Kadir, N.H.N. Hussain, J. Omar, R. Yunus, S. Baie, No.M. Noor, I.I. Hassan, W. H.W. Mahmood, A. Abd Razak and W.Z. Wan Yusoff, 2015. The Effect of Channa striatus (Haruan) extract on pain and wound healing of post-lower segment caesarean section women. Evidence-Based Compl. Alt. Med., 2015, ID 849647, 6 p.

Zuraini, A., M.N. Somchit, M.H. Solihah, Y.M. Goh, A.K. Arifah, M.S. Zakaria and A.M. Mat Jais, 2006. Fatty acid and amino acid composition of three local Malaysian Channa spp. Fish. Food Chem, 97: $674-678$. 